\title{
Influence of gasoline emissions on tomato fruit rot by two fungi in tropical ambient conditions
}

\author{
Abiola Titilola Aborisade*, Kayode Peter Balogun and Oluwole Olakunle Oladele
}

\begin{abstract}
Background: The release of pollutant gases into the atmosphere as a result of anthropogenic activities exert effect on biological systems at many levels. Combustion engines such as those in vehicles and power generators pollute the air with emissions from their exhausts. The gases released which are oxides of carbon, nitrogen; sulphur and particulate matter have effect on living things in the immediate environment. Up to $25 \%$ of harvested fruits and vegetables are lost mainly due to microbial activities before consumption. Disease development in ripe tomato fruit (host) by two of its fungal pathogens in the presence of generator emissions is presently being studied.

Results: Treatment produced variable effects depending on the fungus and the route of infection. For Rhizopus stolonifer coated and Fusarium oxysporum wound inoculated fruits, significant disease reduction was noticeable in the later days of storage, specifically from day 11. Fruits coated with F. oxsporum spores without wounding however, rotted more with gasoline emissions treatment also noticeably at the later period of storage. Long exposures caused greater rot reduction where disease was reduced and more severe rot where disease was enhanced. Rhizopus infected fruits were best preserved for 14 days by 40 min exposure while wound inoculated Fusarium infected fruits were best preserved by 45 min exposure. Disease reduction was $40-50 \%$ in both types of infection. Conversely, disease was most aggravated by about $50 \%$ by 45 min exposure of unwounded Fusarium infected fruits. Other exposures also caused increased rotting by about $5-35 \%$.

Conclusions: The results demonstrate that air pollution by fumes from generators may under certain host-pathogen conditions be advantageous in prolonging postharvest life of ripe tomatoes, while at other times could be devastating when fruits are subsequently stored or marketed at tropical ambient temperature. The advantage, however, outweighs the negative effects.
\end{abstract}

Keywords: Air pollutants, Disease, Fruits, Fungi, Inoculation, Postharvest life

\section{Background}

Anthropogenic emissions from various sources have been recognized as atmospheric pollutants (Fagbeja et al. 2008; Marais et al. 2014). Atmospheric pollution has been reported to have direct and indirect effects on human health (Oguntoke et al. 2010). Other living things and systems in the environment including fungi

\footnotetext{
*Correspondence: biolabo2000@yahoo.com

Department of Biology, The Federal University of Technology, Akure, Nigeria
}

may also be affected by the gases released into the air through human and natural occurrences (Mancinelli and McKay 1983; Wookey et al. 1991). Goods are most often delivered to traders in Nigerian markets by heavy duty vehicles which emit fumes from the exhaust thereby polluting the atmosphere in the immediate vicinity although the gases may also be transferred by the wind far from source. Small and large business holdings located close to or within market areas mostly depend on generators for electricity supply. These also pollute the air with fumes from the power generators. Generators and vehicular 
emissions contain mainly oxides of carbon, nitrogen and sulphur along with hydrocarbons and particulate matter (Tavares et al. 2011; Marais et al. 2014).

In Nigeria, fresh fruits and vegetables are usually displayed openly devoid of protective packaging and sometimes there is need for short and medium-term storage because they are usually not sold out on the day of harvest. They are then kept in largely uncontrolled environments with minimum attempt to keep them away from direct weather conditions. In such situations, the abiotic environment plays a significant role in their postharvest life. It has been recognized that postharvest quality and shelf life of tomatoes really depend on the handling and treatments received after harvest (Arah et al. 2016). Since they always have resident microflora from the field, they are liable to deterioration, the rate of which depends on the biotic and abiotic components of their environment including temperature, humidity and the gaseous atmosphere.

Many fruits commonly distributed or marketed are deteriorated mainly by fungi (Sonoda et al. 1981; Chau and Alvarez 1983; Wenneker and Thomma 2020) but some by bacteria too. Rhizopus stolonifer and Fusarium oxsporum species complex (FOSC) are two of the fungal pathogens reported on tomato fruits (Jin-Hyeuk et al. 2001; Ignjatov et al. 2012; Chehri 2015; John et al. 2016). Ripe tomato fruits sold in most parts of Nigeria are subject to the vagaries of the environment in which they are stored, distributed or marketed. This work is an attempt to assess the effects a polluted atmosphere which is common in cities has on storage life of tomatoes. Despite the vast literature on air pollution and the effects on living things, there is paucity of information on specific effects that such pollution may have on postharvest life of fresh plant produce. The effects that the gaseous emissions contained in generator fumes have on disease development and consequently storability of tomato fruits infected by $R$. stolonifer and F. oxsporum is being presently investigated.

\section{Methods}

\section{Plant material preparation, inoculation and treatment}

This study was carried out using healthy Roma tomato fruits at the fourth (light red) stage of ripening. The identification was by the authors. Fruits were obtained from Shasha wholesale market in Akure. The fruits were surface disinfected in $0.385 \% \mathrm{~m} / \mathrm{v}$ sodium hypochlorite for $10 \mathrm{~min}$ after sorting. For inoculation without wounding, whole unbroken and uninfected surface disinfected fruits were immersed in spore suspensions of the fungi for $10 \mathrm{~s}$ for spores attachment to fruit surface. This is described as coating fruits with fungal spores. Spore suspensions used contained $3.7 \times 10^{6}$ spores $/ \mathrm{ml}$ of $R$. stolonifer and
$2.6 \times 10^{6}$ spores $/ \mathrm{ml}$ of $F$. oxysporum in coating separate fruits.

The shoulder of each healthy, unbroken fruit was then inoculated by lacerating with sterilized needle dipped into spore suspension containing $2.6 \times 10^{6}$ spores $/ \mathrm{ml}$ of $F$. oxysporum. The laceration was $0.5 \mathrm{~cm}$ in length. This was the wound inoculation procedure adopted (for $F$. oxsporum only).

After inoculation, individual fruits placed in sterile open Petri plates were placed in airtight wooden boxes filled with fumes of gasoline emissions from a power generator for 5 to $45 \mathrm{~min}$ (Balogun et al. 2020). After treatments, the plates containing the fruits were stored at saturated relative humidity in sterilized glass desiccators and kept at tropical ambient temperature $\left(28 \pm 2{ }^{\circ} \mathrm{C}\right)$. Disease severity was assessed on individual fruit daily, and rated (Aborisade and Ojo 2002; modified) from 1 to $5(1=$ no symptom, $2=$ symptom on $\leq 10 \%$ fruit area, $3=$ rot on $20-30 \%$ fruit surface, $4=$ rot on $50 \%$ fruit surface, $5=$ rot on $\geq 70 \%$ fruit surface). Disease symptom for $R$. stolonifer was soft rot characterized by translucence due to internal tissue maceration and greyish/black whiskers appearance at advanced stage. For F. oxysporum, disease was evidenced by fruit softening due to water retention without translucence and appearance of white fluffy cottony mycelium on fruits at the advanced stage. Controls were set up by inoculating fruits and storing without exposure to fuel emissions prior to storage.

\section{Statistical analysis}

All treatments were performed in five replicates and data analyzed by one-way ANOVA. Where significant, means were separated by Duncan's New Multiple Range Test at $\alpha=0.05$.

\section{Results}

The emissions significantly reduced disease severity on tomato fruits coated with spores of $R$. stolonifer. The effect was not noticeable in the early days of storage but by day 11 , the reduction was noticeable on fruits exposed for $40 \mathrm{~min}$. Those fruits had rot symptoms on $<15 \%$ fruit surface while control was more than $65 \%$ rotten. Some exposures, however, aggravated rot development. Such exposures were at 20 and $30 \mathrm{~min}$ from days 4 and 10, respectively. Rot progression in control initially slow in the first 7 days reaching $<30 \%$ surface infection, eventually progressed to total rot by day 14 . Fruits exposed for 20 and 30 min were completely rotted on days 11 and 12 respectively while those exposed for $25 \mathrm{~min}$ were completely rotted on day 13 ((Fig. 1).

On fruits coated with $F$. oxsporum however, emissions increased disease severity significantly from day 11 to 13 although statistically insignificant greater disease 


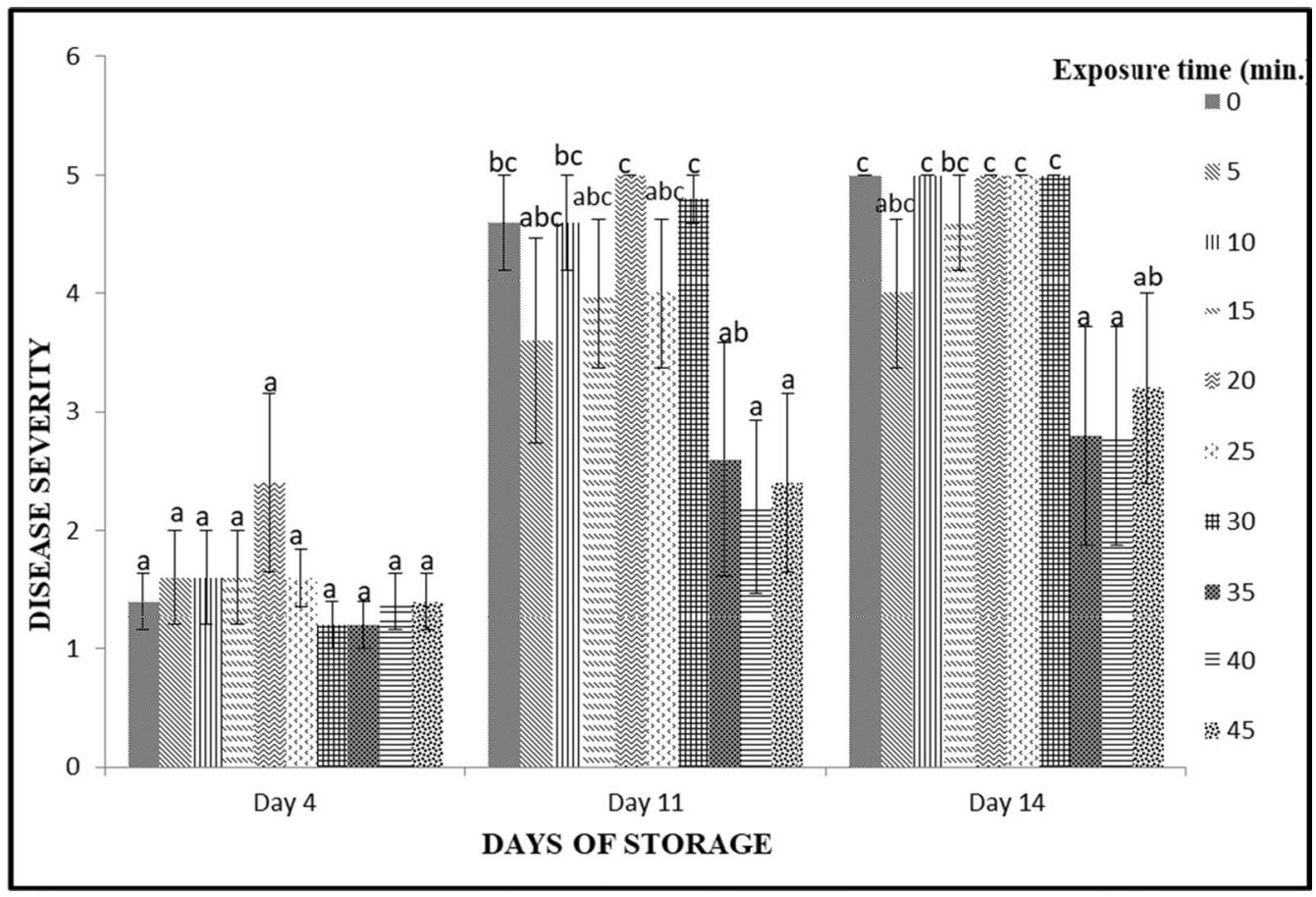

Fig. 1 Effect of exposure to gasoline fuel emission on severity of rot caused by Rhizopus stolonifer on ripe tomato fruits

severity compared to control was observed from day 7 on all exposed fruits except those treated for $10 \mathrm{~min}$. The increase was from first appearance of symptoms on $<10 \%$ fruit surface in control to $>60 \%$ rot on fruits exposed for 45 min representing slightly $>50 \%$ increase. Rot progressed very slowly on Fusarium coated control fruits over the 14-day storage reaching $<10 \%$ surface infection while it progressed to $\sim 65 \%$ infection on fruits exposed for $45 \mathrm{~min}$ within the same period of storage. All other exposures resulted into more rot progression than control but not as much as the 45 min exposure (Fig. 2). The rot progression was 5-35\% more than the control.

Fruits wound inoculated with $F$. oxsporum and exposed for 5,15 , and $25-45$ min showed slightly significant disease reduction on day 1 of storage. Thereafter, there was no statistically significant effect though disease severity was consistently lower at the higher exposure periods of 25-45 min when compared with control from day 10 to 14 . This represented $\sim 40 \%$ reduction particularly at $45 \mathrm{~min}$ exposure from day 11 . There were inconsistent evidences of rot reduction with increase in length of exposure to emissions at other periods too. Although the control fruits showed disease symptoms from day 1 , disease progression was very slow increasing to $~ 30 \%$ rotted surface in 10 days but thereafter increasing fairly rapidly in the next three days. Fusarium wound inoculated fruits exposed for 45 min did not show rot symptoms until day
6 and then it progressed very slowly to $10 \%$ infected surface on day 14 (Fig. 3). Severity was noticeably low even on control unwounded Fusarium infected fruits throughout the 14-day storage while control wounded fruits presented a similar course until day 11 when rot increased more rapidly.

\section{Discussion}

The more severe rot observed on wounded controls in comparison with unwounded controls of Fusarium infected fruits supports earlier reports that injuries predispose plants to infection (Hong et al. 1998). The observed results on both methods of introducing the pathogen unto host followed with gasoline emissions treatment however strongly give support to the fact that disease development is a complex interplay of several factors (Liu et al. 2018) which change with prevailing conditions while minor components also exert effect. This implies that results may not always be predictable although specific processes, steps and roles may be identifiable. Varied effects of $\mathrm{SO}_{2}$ gas and nitrogen oxides were reported on diseases by pathogenic fungi (Khan and Khan 2011; Orr and Nelson 2018). This is quite significant because development of more severe rot on wounded fruits than unwounded was in spite of the likely higher inoculum density on unwounded Fusarium inoculated than wounded fruits due to the methods of their 


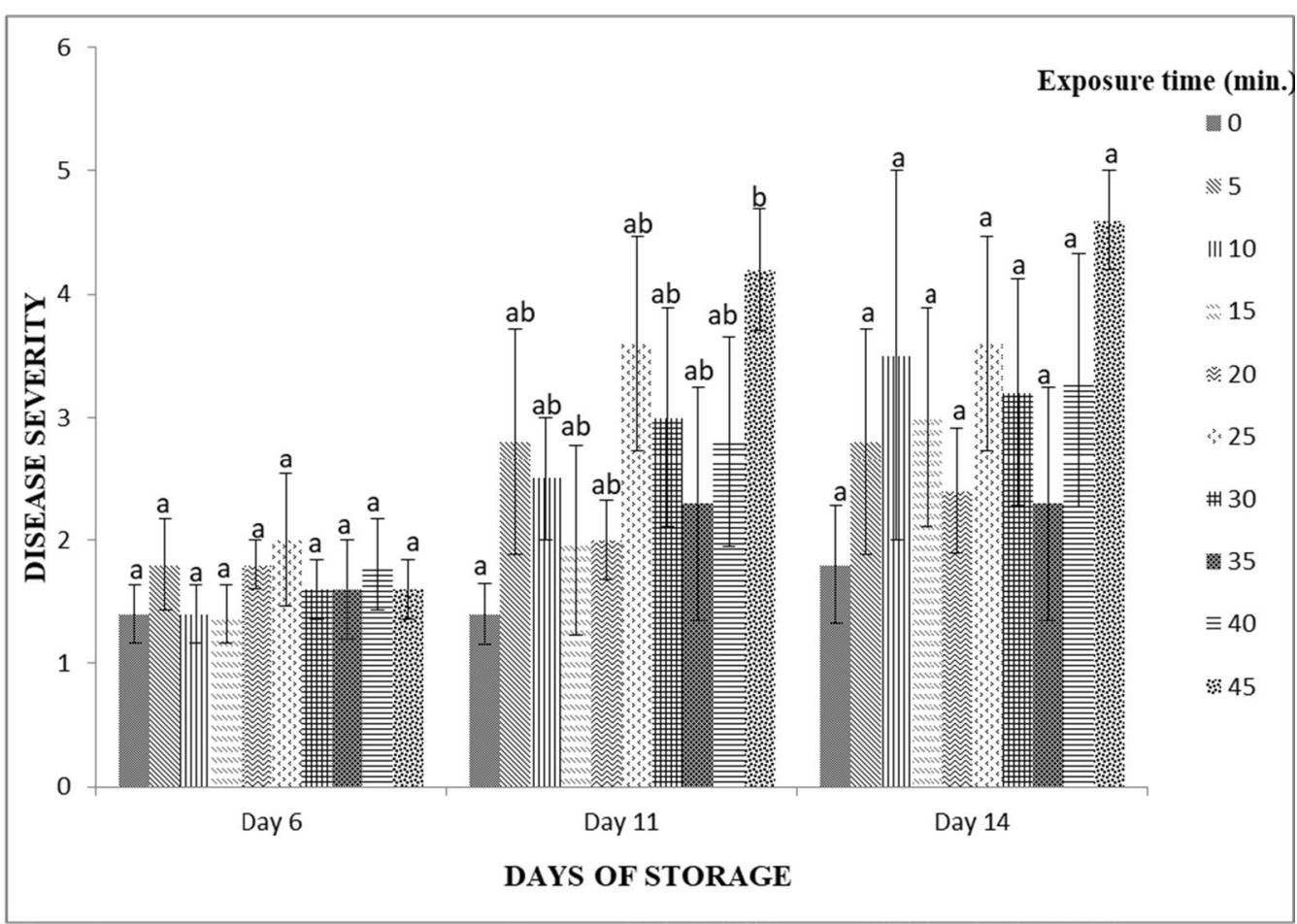

Fig. 2 Effect of exposure to gasoline fuel emission on severity of rot caused by Fusarium oxysporum on unwounded tomato fruits

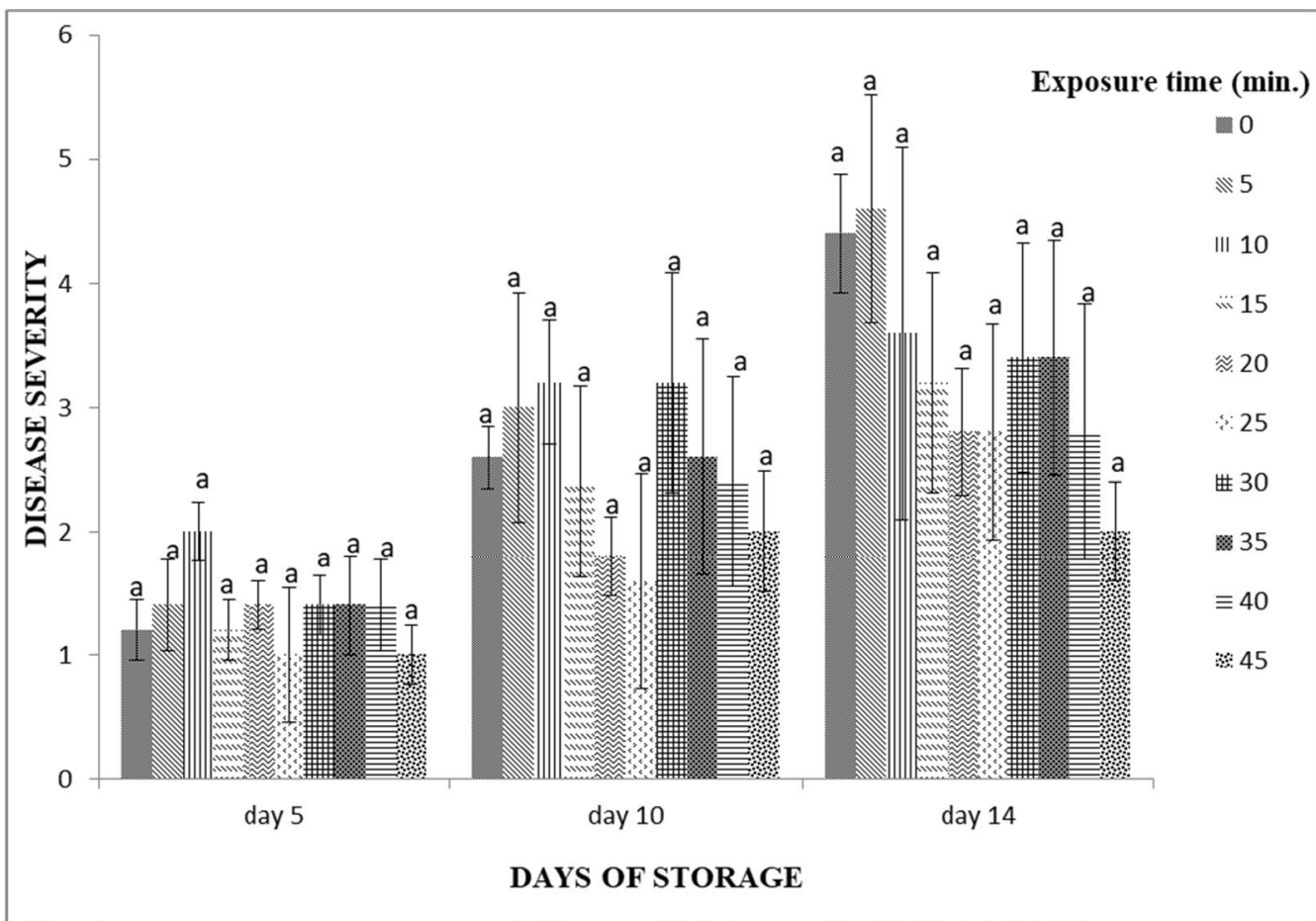

Fig. 3 Effect of exposure to gasoline fuel emission on severity of rot on tomato fruits wound inoculated with Fusarium oxysporum 
inoculation. Wounded peach and plum fruits with only two spores of Monilinia fructico!a were also reported to develop rot (Hong et al. 1998). It was expected that higher inoculum should produce more severe rot. Increased tomato fruit rot was earlier reported with increased inoculum (Silveira et al. 2001). It was however demonstrated that wounds on tomato fruits allowed spores of $R$. stolonifer to be carried into intercellular spaces in the tissue resulting into rot even though the spores on fruit surface were killed by chlorination during fruit disinfection (Bartz et al. 2001) as pollutant gases in the emissions may have also killed spores on the surface.

The observed increased rot severity with increase in length of exposure to fuel emissions especially at longer days of storage on fruits coated with Fusarium spores, show that Fusarium spores were probably more stimulated than inhibited to grow in vivo. For wounded fruits however, the disease reduction though insignificant, suggest that tomato fruit exudates released through the wound, probably played inhibitory role in Fusarium colonization of the fruit tissues. The inhibition might also be due to mixing of fruit exudate with fumes from the generator exhaust. This is an indication that the combination of fruit exudates and emitted gases were inhibitory to growth of Fusarium in a synergistic mode, in addition to their individual inhibitory roles while the absence of tomato exudates allowed emissions to favour growth of Fusarium on the fruits. The latter is an indication that once the spores germinated on fruit surface, disease progressed normally by fungal enzymes activities and emitted gases therefore had reduced effect. This suggests that Fusarium might have modified its infection strategy in response to host conditions. This observation is contrary to the general knowledge that injuries predispose plant hosts to infection. It was also reported that wounding protected Arabidopsis leaves from hyphal growth of Botrytis cinerea a necrotrophic pathogen like Rhizopus and Fusarium (Chassot et al. 2008). Though the injuries served as port of entry into the host, the fungus could not grow. It is probable that spore germination was poor on wounded fruit because of acidity of the tomato fruit juice. The neutral $\mathrm{pH}$ on the surfaces of intact fruits however permitted higher germination percentage and since cell wall degrading enzymes were produced at the tips of hyphae, after spore germination, disease progression occurred faster than on wounded fruits where germination was low, hence rot reduction.

The little rot reduction observed with increase in length of exposure to gasoline emissions observed on Rhizopus infected fruits also show that the spores germinated poorly and the germ tubes grew poorly causing the observed rot reduction. Poor spore germination and inhibited germ tube growth were reported for $R$. stolonifer exposed to generator fumes (Balogun et al. 2020). The suppression might be due mainly to low oxygen, high $\mathrm{CO}_{2}$ with carbon monoxide contained in the gasoline fumes. Such conditions were reported to be fungistatic (Sommer et al. 1980). Low concentrations of carbon monoxide reduced disease incidence on peach after harvest (Zhang et al. 2014).

These results indicate that while gasoline emissions could be detrimental to unbroken ripe Fusarium coated ripe tomato fruits, it could at the same time serve to extend the life of Fusarium infected broken tomatoes and those coated with $R$. stolonifer such that postharvest losses can be reduced. This could be advantageous in storage as it might reduce economic losses especially on the part of retailers. Pollutant gases in the atmosphere such as those from vehicles and generators might therefore have some benefit on harvested crops. Gasoline emissions have been reported to contain carbon monoxide, carbon dioxide, oxides of nitrogen, and sulphur dioxide (Tavares et al. 2011; Marais et al. 2014) which form both weak and moderately strong acids in solution. The acids formed by the emitted gases coupled with tomato fruit acidity probably made the fruit unfavorable for the macerating enzymes of $F$. oxsporum to act optimally for disease development on wounded fruits. The acids formed probably also contributed to disease reduction specifically the vegetative growth of the fungus within the fruit in addition to the initial inhibition of germination.

The variable effects of gasoline emissions on rot of infected ripe tomato fruits here reported is indication that there is need for more investigation in order to ascertain the definite influence of pollutant gases from gasoline combustion on postharvest quality of tomatoes. This is important in view of the significant increase of pollutant gases in the atmosphere which through minimally processed food such as fresh tomatoes, may produce indirect effects on humans.

\section{Conclusions}

Exposure to pollutant fumes from generator exhaust influenced disease development on tomato fruits. Though the exposure period tested was brief, the intensity of emission was high, signaling the fact that the normal long-term exposure of tomatoes during display and marketing, must have effect on health of fruits and consequently on shelf life. The effects however seemed to depend on the presence or absence of wounds on fruit and the pathogen involved.

\section{Acknowledgements \\ Not applicable}

\section{Authors' contributions}

The manuscript was prepared by ATA who also supervised data collection and statistical analysis by KPB. All authors including OOO have read and approved 
the manuscript. AAT's contribution was $40 \%$, KPB contributed $40 \%$ and OOO contributed $20 \%$ to the work. All authors read and approved the final manuscript.

\section{Authors' information}

ATA and $\mathrm{OOO}$ hold positions as lecturers in Biology with interest in postharvest pathology/mycology and they are both members of the Nigerian Society for Plant protection. KPB is a graduate student of Environmental Biology.

\section{Funding}

Not applicable.

\section{Availability of data and materials}

All data generated and analyzed during the study are included in this published article.

\section{Declarations}

Ethics approval and consent to participate

Not applicable.

\section{Consent for publication}

Not applicable.

\section{Competing interests}

The authors declare that they have no competing interests.

Received: 28 March 2021 Accepted: 3 June 2021

Published online: 12 June 2021

\section{References}

Aborisade AT, Ojo FH (2002) Effect of postharvest hot air treatment of tomatoes (Lycopersicon esculentum. Mill) on storage life and decay caused by Rhizopus stolonifer. J Plant Dis Prot 109:639-645

Arah IK, Ahorbo GK, Anku EK, Kumah EK, Amaglo H (2016) Postharvest handling practices and treatment methods for tomato handlers in developing countries: a mini review. Adv Agric. https://doi.org/10.1155/ 2016/6436945

Balogun KP, Aborisade AT, Oladele OO (2020) Impact of gasoline fuel emissions on Rhizopus stolonifer (Ehrenb.) Vuill. and Fusarium oxysporum (Schlecht.). Bull Nat Res Centre 44:147. https://doi.org/10.1186/s42269-020-00406-9

Bartz J, Eayre CG, Mahovic MJ, Concelmo DE, Brecht JK, Sargent, (2001) Chlorine concentration and the inoculation of tomato fruit in packinghouse dump tanks. Plant Dis 85:885-889

Chassot C, Buchala A, Schoonbeek H, Metraux J, Lamotte O (2008) Wounding of Arabidopsis leaves causes a powerful but transient protection against Botrytis infection. Plant J 55(4):555-567. https://doi.org/10.1111/j.1365313x.2008.03540.x

Chau KF, Alvarez AM (1983) Postharvest fruit rot of papaya caused by Stemphylum lycopersici. Plant Dis 67:1279-1281

Chehri K (2015) First report of postharvest fruit rot of tomato caused by Fusarium oxysporum in Iran. Arch Phytopathol Plant Prot 48(6):537-544

Fagbeja MA, Chatterton TJ, Longhurst JWS, Akinyede JO, Adegoke JO (2008) Air pollution and management in the Niger Delta-emerging issues. Trans Ecol Environ 116:207-216. https://doi.org/10.2495/AIR080221
Hong C, Michailides TJ, Holtz BA (1998) Effects of wounding, inoculum density, and biological control agents on postharvest Brown rot of stone fruits. Plant Dis 82(11):1210-1216

Ignjatov M, Milosevic D, Nikolic Z, Gvozdanovic-Varga J, Jovicic D, Zdjelar G (2012) Fusarium oxsporum as causal agent of tomato wilt and fruit rot. Pestic Phytomed 27(1):25-31

Jin-Hyeuk K, Soo-Woong K, Jeong-Soo K, Chang-Seuk P (2001) Rhizopus soft rot on Cherry tomato caused by Rhizopus stolonifer in Korea. Mycobiology 29(3):176-178. https://doi.org/10.1080/12298093.2001.12015783

John WC, Anyanwu NCJ, Ogunmodi OA (2016) Determination of pathogenic effect of fungi on fresh healthy tomatoes in Jos North Local Government Area, Plateau State, Nigeria. Annu Res Rev Biol 9(5):1-8. https://doi.org/10. 9734/ARRB/2016/23689

Khan MR, Khan MM (2011) Plant response to diseases in sulphur dioxide stressed environment. Plant Pathol J 10(1):1-12

Liu J, Sui Y, Wisniewski M, Xie Z, Liu Y, You Y, Zhang X, Sun Z, Li W, Li Y, Wang Q (2018) The impact of the postharvest environment on the viability and virulence of decay fungi. Crit Rev Food Sci Nutr 58(10):1681-1687. https://doi.org/10.1080/10408398.2017.1279122

Mancinelli RL, McKay CP (1983) Effects of nitric oxide and nitrogen dioxide on bacterial growth. Appl Environ Microbiol 46(1):198-202

Marais EA, Jacob DJ, Wecht K, Lerot C, Zhang L, Yu K, Kurosu TP, Chance K, Sauvage $B$ (2014) Anthropogenic emissions in Nigeria and implications for atmospheric ozone pollution: a view from space. Atmos Environ 99:32-40

Oguntoke O, Opeolu BO, Babatunde N (2010) Indoor air pollution and health risks among rural dwellers in Odeda area, South-Western Nigeria. Ethiopian J Environ Stud Manag 3(2):39-46

Orr R, Nelson PN (2018) Impact of soil abiotic attributes on Fusarium wilt, focusing on bananas. Appl Soil Ecol 132:20-33

Silveira NSS, Michereff SJ, Mariano RLR, Tavares LA, Maia LC (2001) Influence of temperature, wetness period and fungal inoculums concentration on incidence of postharvest tomato fruit rots. Fitopatol Bras 26(1):33-38

Sommer NF, Kader AA, Buchanan JR, Mitchell FG, Fortlage RJ (1980) Modified atmospheres with carbon monoxide for suppression of rot of perishable fruits and vegetables in storage and transit. Proc Trop Reg Amer Soc Hort Sci 24:113-116

Sonoda RM, Hayslip NC, Stofella PJ (1981) Tomato fruit rot infection cycle in a fresh market packing operation. Proc Fla State Hort Soc 94:281-282

Tavares JR, Sthel MS, Campos LS, Rocha MV, Lima GR, da Silva MG, Vargas H (2011) Evaluation of pollutant gases emitted by ethanol and gasoline powered vehicles. Proc Environ Sci 4:51-60

Wenneker M, Thomma BPHJ (2020) Latent postharvest pathogens of some fruits and their management: from single measures to a systems intervention approach. Eur J Plant Pathol 156:663-681

Wookey PA, Ineson P, Mansfield TA (1991) Effects of atmospheric sulphur dioxide on microbial activity in decomposing forest litter. Agr Ecosyst Environ 33(3):263-280. https://doi.org/10.1026/0167.8809(91)90006-J

Zhang S, Li Y, Fei P (2014) Carbon monoxide fumigation improved the quality, nutrients and antioxidant activities of postharvest peach. Int J Food Sci 4:11-17. https://doi.org/10.1155/2014/834150

\section{Publisher's Note}

Springer Nature remains neutral with regard to jurisdictional claims in published maps and institutional affiliations. 